\title{
One-step percutaneous transhepatic cholangioscopy combined with high-frequency needle-knife electrotomy in biliary strictures after liver transplantation
}

\author{
Haisu Tao \\ Tongji Hospital, Tongji Medical College, Huazhong University of Science and Technology \\ Ping Wang ( $\nabla$ wangping_dr@126.com ) \\ The First Affiliated Hospital of Guangzhou Medical University, Guangdong Province \\ Beiwang Sun \\ Department of Hepatobiliary Surgery, The First Affiliated Hospital of Guangzhou Medical University \\ Xinghua Zhou \\ Department of Hepatobiliary Surgery, The First Affiliated Hospital of Guangzhou Medical University

\section{Jiafen Xie} \\ Department of Hepatobiliary Surgery, The First Affiliated Hospital of Guangzhou Medical University
}

\section{Research article}

Keywords: PTCSL, electrotomy, biliary strictures, liver transplantation

Posted Date: May 9th, 2020

DOI: https://doi.org/10.21203/rs.3.rs-25528/v1

License: (우 This work is licensed under a Creative Commons Attribution 4.0 International License. Read Full License

Version of Record: A version of this preprint was published at Surgical Laparoscopy, Endoscopy \& Percutaneous Techniques on May 3rd, 2021. See the published version at https://doi.org/10.1097/SLE.0000000000000946. 


\section{Abstract \\ Background}

Endoscopic management is the mainstay for biliary strictures after liver transplantation. However, this method is often failed in cases associated with hepatolithiasis or refractory strictures. The aim of this study is to investigate whether one-step PTC combined with highfrequency needle-knife electrotomy can be an alternative method in biliary strictures after liver transplantation that could not be treated by endoscopic management.

\section{Methods}

Clinical data of 14 patients suffering from biliary strictures after liver transplantation from June 2014 to January 2018 were retrospectively analyzed. One-step PTC combined with high-frequency needle-knife electrotomy was used to resolve the strictures.

\section{Results}

One-step PTC was successfully performed in all 14 patients. In 10 of 12 (83.3\%) patients with hepatolithiasis, the stones were removed completely. The stricture resolution was achieved in 13 of 14 (92.9\%) patients at supporting catheter removal. Three mild adverse events occurred (cholangitis, 2 patient; delayed hemobilia, 1 patient), but were resolved with conservative treatment. The follow up after supporting catheter removal was $15.7 \pm 4.5$ months. Only 1 patient $(8.3 \%)$ had stone recurrence and no stenosis occurred during supporting-free follow-up.

\section{Conclusion}

One-step PTC combined with high-frequency needle-knife electrotomy appears to be a useful for treating biliary strictures after liver transplantation.

\section{Introduction}

Orthotopic liver transplantation (OLT) is the main treatment for patients with end-stage liver disease of different etiologies, hepatocellular carcinoma(HCC), and acute liver failure[1,2] Biliary strictures represent the most frequent biliary complication after liver transplantation, accounting for approximately $40 \%$ of all biliary complications [3-5]. Endoscopic management is usually the first-line treatment for biliary strictures complicating OLT and includes endoscopic retrograde cholangiography(ERC), biliary sphincterotomy and stent placement (with or without balloon dilatation) [6-8].

However, there are some cases that ERC can't handle. For example, the success rate of ERC for patients with hepatolithiasis is low, particularly in those with widespread or large calculi [9-10]. Besides, some refractory strictures, such as "tubular stricture" characterized as a columnar stenosis of bile duct more than $5 \mathrm{~mm}$, are often failed in balloon dilatation and stent placement [11]. These cases are even hard to tackle by traditional percutaneous transhepatic biliary drainage (PTCD), which use balloon or basket to treat strictures and stones under the guidance of cholangiography [6].

With the aid of a new method, percutaneous transhepatic one-step biliary fistulation (PTOBF) [12-13], choledochoscope can be used to treat strictures and hepatolithiasis at the same time. Through cholangioscopy, high-frequency needle-knife electrotomy can be performed to resolve refractory strictures[11], which are difficult to be relieved only via balloon dilatation and stent.

As far as we known, no literature has reported how to treat hepatolithiasis associated with biliary strictures after liver transplantation. We are the first group to use PTC combined with high-frequency needle-knife electrotomy in treating biliary strictures after liver transplantation. The purpose of this study was to report the results of one-step PTC combined with high-frequency needle-knife electrotomy to treat biliary strictures after liver transplantation.

\section{Methods}

\section{Ethics statement}


This retrospective study and the included supervised procedures were approved by the Ethics Committee of the First Affiliated Hospital of Guangzhou Medical University (Guangzhou Province, China). All patients involved in this study gave their informed consent and institutional review board approval of our hospital was obtained for this study.

\section{Patients}

From June 2014 to January 2018, 14 patients of biliary strictures after liver transplantation were enrolled in the study. These patients had failed in ERC or were not suitable for ERC approach due to large stone size or presence of multiple stones. Hepatolithiasis and biliary strictures were diagnosed by preprocedural magnetic retrograde cholangiopancreatography (MRCP) which was performed in all patients.

\section{Procedure Details}

\section{PTOBF And Establishing Channel For The Rigid Choledochoscope}

Under the guidance of intraoperative ultrasonography (IOUS), biliary tract puncture was performed. Then, the zebra guidewire was placed into intrahepatic duct. With the guidance of the zebra guidewire, the sinus was immediately expanded by the biliary expanders step-bystep until it could hold a 14-Fr or 16-Fr protective sheath. In this way, a working channel for the rigid choledochoscope was established(figure1).

\section{Choledochoscopic Highfrequency Needle-knife Electrotomy And Balloon Dilatation}

When a stenosis was confirmed with choledochoscope and cholangiography, highfrequency needle-knife was inserted into the restricted bile duct through the protective sheath. Choledochoscopic highfrequency needle-knife electrotomy was performed using a highfrequency generator with a setting of mixed currents, cut current of 40-W, coagulation current of 40-W(figure2). All operational manipulations were performed within the center of the visual fields, and direct contact with the biliary ducts was avoided. After the stricture was cut open, a 4 , 6 or $8 \mathrm{~mm}$ balloon dilatation catheter which was selected according to the diameter of the bile duct proximal to the stricture, was then inserted under the guidance of the zebra guidewire. The balloon was manually inflated until the balloon waist is eliminated and was kept inflated for 1-3 minutes. Then, cholangiogram was performed to evaluate the effect of dilatation.

\section{Choledochoscopic Lithotripsy And Supporting Catheter Insertion}

With the aid of rigid choledochoscope, electrohydraulic lithotripsy $(E H L)$ could be applied to fragment large and hard stones. Small stones can be directly flushed out with the washing function of the rigid choledochoscope. The remaining larger stones could also be removed with a basket or a clamp(figure3). After the stones were removed clearly, a drainage catheter with multiple side holes was placed across the stricture. $12 \mathrm{Fr}$ catheter was usually used and catheter exchange was performed every 2-3 months. This drainage catheter can also function as supporting catheter. The catheter was removed 6 to 9 months after PTC if the stricture was resolved on a follow-up cholangiogram.

\section{Outcome Measurement}

Membranous stricture was defined as a layer of fibrous membrane with a narrow opening in the center. Tubular stricture was defined as a narrow lumen of bile duct more than $5 \mathrm{~mm}$.

Stricture resolution was defined as no or only a minimum waist discerned on cholangiography without clinical symptoms including jaundice after stent removal or migration requiring an endoscopic re-intervention for the biliary stricture. Recurrent stricture was defined as elevated liver enzymes or cholangitis requiring an endoscopic re-intervention for the biliary stricture [14-15]. All patients were placed under regular follow-up, with periodic monitoring of clinical conditions by biochemical testing and imaging examination (CT/MRCP/ cholangiogram). 
Results

\section{Patient Characteristics}

The mean age of the 14 patients was $44 \pm 15.1$ years. There were 10 male patients and 4 female patients. 9 patients received preoperative ERC but failed in treating hepatolithiasis and biliary strictures. Of these, 2 patients received PTCD approach as a rescue therapy, but failed again. MRCP, cholangiography and choledochoscope findings were combined to diagnose hepatolithiasis and biliary strictures accurately. 12 patients were diagnosed with hepatolithiasis and biliary strictures, and the number of stone was 2 in $3(25 \%), 3$ in $2(16.7 \%)$ and more than 3 in 7 (58.3\%) patients. The stone locations were in the right bile ducts in 4 (33.3\%), left bile ducts in 5 (41.7\%), and both in $3(25 \%)$ patients. The maximum mean stone diameter was $7.6 \pm 2.3 \mathrm{~mm}$. The number of single and multiple bile duct strictures was 12 and 2 , respectively(Table 1 ).

Table 1

Characteristics of the patients

\begin{tabular}{|c|c|c|c|c|c|c|c|c|c|}
\hline $\begin{array}{l}\text { Patient } \\
\text { no. }\end{array}$ & $\begin{array}{l}\text { Preoperative } \\
\text { ERC/PTCD }\end{array}$ & $\begin{array}{l}\text { Stone } \\
\text { location }\end{array}$ & $\begin{array}{l}\text { Maximum } \\
\text { size of } \\
\text { stone } \\
(\mathrm{mm})\end{array}$ & $\begin{array}{l}\text { No.of } \\
\text { Stones }\end{array}$ & Stricture type & Stricture site & $\begin{array}{l}\text { No.of } \\
\text { Strictures }\end{array}$ & $\begin{array}{l}\text { Treatment } \\
\text { of stone }\end{array}$ & $\begin{array}{l}\text { Treatment } \\
\text { of stricture }\end{array}$ \\
\hline 1 & ERC & Left & 8 & $\triangle 3$ & Tubular & anastomosis & 1 & $\begin{array}{l}\text { EHL and } \\
\text { basket }\end{array}$ & $\begin{array}{l}\text { electrotomy } \\
\text { and } \\
\text { balloon }\end{array}$ \\
\hline 2 & ERC & Rigtht & 6 & 2 & Membranous & anastomosis & 1 & basket & electrotomy \\
\hline 3 & None & Both & 10 & 3 & Membranous & $\begin{array}{l}\text { Left hepatic } \\
\text { duct and } \\
\text { anastomosis }\end{array}$ & 2 & $\begin{array}{l}\text { EHL and } \\
\text { basket }\end{array}$ & $\begin{array}{l}\text { electrotomy } \\
\text { and } \\
\text { balloon }\end{array}$ \\
\hline 4 & ERC & Rigtht & 12 & 2 & Membranous & anastomosis & 1 & $\begin{array}{l}\text { EHL and } \\
\text { basket }\end{array}$ & electrotomy \\
\hline 5 & None & Both & 6 & $\unrhd 3$ & Membranous & anastomosis & 1 & basket & electrotomy \\
\hline 6 & ERC & Left & 8 & 3 & Membranous & $\begin{array}{l}\text { Left hepatic } \\
\text { duct and } \\
\text { anastomosis }\end{array}$ & 2 & $\begin{array}{l}\text { EHL and } \\
\text { basket }\end{array}$ & $\begin{array}{l}\text { electrotomy } \\
\text { and } \\
\text { balloon }\end{array}$ \\
\hline 7 & None & Both & 6 & $\nabla 3$ & Membranous & anastomosis & 1 & basket & electrotomy \\
\hline 8 & None & Right & 11 & $\nabla 3$ & Membranous & anastomosis & 1 & $\begin{array}{l}\text { EHL and } \\
\text { basket }\end{array}$ & electrotomy \\
\hline 9 & ERC & None & - & - & Tubular & anastomosis & 1 & - & $\begin{array}{l}\text { electrotomy } \\
\text { and } \\
\text { balloon }\end{array}$ \\
\hline 10 & ERC & Left & 8 & 2 & Membranous & anastomosis & 1 & $\begin{array}{l}\text { EHL and } \\
\text { basket }\end{array}$ & electrotomy \\
\hline 11 & ERC & Left & 6 & $\varangle 3$ & Membranous & anastomosis & 1 & basket & electrotomy \\
\hline 12 & $\begin{array}{l}\text { ERC and } \\
\text { PTCD }\end{array}$ & None & - & - & Tubular & anastomosis & 1 & - & $\begin{array}{l}\text { electrotomy } \\
\text { and } \\
\text { balloon }\end{array}$ \\
\hline 13 & $\begin{array}{l}\text { ERC and } \\
\text { PTCD }\end{array}$ & Left & 4 & $\otimes 3$ & Tubular & anastomosis & 1 & basket & $\begin{array}{l}\text { electrotomy } \\
\text { and } \\
\text { balloon }\end{array}$ \\
\hline 14 & None & Rigtht & 6 & $\otimes 3$ & Tubular & anastomosis & 1 & $\begin{array}{l}\text { EHL and } \\
\text { basket }\end{array}$ & $\begin{array}{l}\text { electrotomy } \\
\text { and } \\
\text { balloon }\end{array}$ \\
\hline
\end{tabular}

\section{Procedural outcomes and follow-up}

One-step PTC was successfully performed in all 14 patients. In 10 of $12(83.3 \%)$ patients with hepatolithiasis, the stones were removed completely using a EHL or basket. 4 patients received basket alone $(5 / 12 ; 41.7 \%)$ and 8 patients $(7 / 12 ; 58.3 \%)$ underwent simultaneous 
procedures including basket and EHL. The two patients with incomplete fragment clearance received additional stone extraction manipulations at a later date, and all residual stones were removed at last. The median duration of supporting catheter therapy was $7.1 \pm$ 1.2 months. The stricture resolution was achieved in 13 of 14 (92.9\%) patients at supporting catheter removal(Table 2). That patient without stricture resolution received a additional electrotomy and balloon dilatation via choledochoscope.

Table 2

Procedural outcomes and follow-up

\begin{tabular}{|llllllll|}
\hline $\begin{array}{l}\text { Patient } \\
\text { no. }\end{array}$ & $\begin{array}{l}\text { Residual } \\
\text { stone }\end{array}$ & $\begin{array}{l}\text { Stricture } \\
\text { resolution }\end{array}$ & Complications & $\begin{array}{l}\text { Duration of supporting } \\
\text { catheter (mo) }\end{array}$ & $\begin{array}{l}\text { Catheter-free } \\
\text { follow-up (mo) }\end{array}$ & $\begin{array}{l}\text { Recurrent } \\
\text { stricture }\end{array}$ & $\begin{array}{l}\text { Recurrent } \\
\text { stone }\end{array}$ \\
\hline 1 & No & Yes & None & 6 & 18 & No & No \\
\hline 2 & No & Yes & None & 8 & 10 & No & - \\
\hline 3 & Yes & No & Cholangitis & 8 & - & No & No \\
\hline 4 & No & Yes & None & 6 & 22 & No & No \\
\hline 5 & No & Yes & None & 6 & 14 & No & No \\
\hline 6 & No & Yes & None & 9 & 13 & No & No \\
\hline 7 & Yes & Yes & Cholangitis & 6 & 12 & No & - \\
\hline 8 & No & Yes & None & 7 & 13 & No & No \\
\hline 9 & - & Yes & Delayed & 6 & 13 & Nes \\
\hline 10 & No & Yes & None & 8 & 23 & No & - \\
\hline 11 & No & Yes & None & 8 & Died at 5 months & No & No \\
\hline 12 & - & Yes & None & 7 & 11 & No & No \\
\hline 13 & No & Yes & None & 6 & 9 & 19 & No \\
\hline 14 & No & Yes & None & 9 & & No & No \\
\hline
\end{tabular}

The follow up after supporting catheter removal was $15.7 \pm 4.5$ months. One patient died during the catheter-free follow-up period at 5 months from HCC recurrence. After the operations, 2 cases of cholangitis (2/14,14.2\%), 1 cases of delayed hemobilia (1/14, 7.1\%), but were resolved with conservative treatment. During the follow-up time, only 1 patient (8.3\%) had stone recurrence(Table 2 ). No stenosis occurred during supporting-free follow-up.

\section{Discussion}

Biliary strictures are common complications after orthotopic liver transplantation[6]. The standard therapy for these strictures is balloon dilation followed by the insertion of stents via the ERC approach. In cases of failed ERC, PTCD approach is considered as alternative therapy. These methods are effective in most patients, but may fail in some special cases[16-17].

Firstly, the insufficiency of maneuverable devices to remove the distal intrahepatic stones through ERC approach, contribute to the failure of stone clearance, especially for widespread or large calculi. Conventional PTCD approach, which use balloon or basket to clear stones under the guidance of cholangiography, is also unable to tackle widespread and large calculi. Fortunately, a working channel for the rigid choledochoscope can be established with the aid of PTOBF. Through choledochoscope, various methods, such as constant irrigation, basket extraction and lithotripsy, can be used to eliminate calculi efficiently. In our 12 patients with hepatolithiasis, the immediate stone clearance success rate was $83.3 \%(10 / 12)$. With additional stone extraction via choledochoscope, all residual stones were removed. During the follow-up time, only 1 patient (8.3\%) had stone recurrence with an anastomotic stricture. Reported rates of successful stone clearance via PTC approach are variable. Some studies published that the complete clearance of hepatolithiasis after percutaneous treatment were $76-85 \%$, and the stone recurrence rate were $16-30 \%$ at a median follow-up period of 3-5 years[18-20]. Although our results may seem similar, they are not comparable as no published study has focused solely on intrahepatic calculi after liver transplantation. 
What's more, it can be found in endoscopic management that balloon expansion, guidewire, ductal dilatation, and stenting cannot be placed into stenotic bile duct through the stricture when the bile duct is filled with stones or when the bile duct is too narrow or too long. For these biliary strictures, choledochoscopic needle-knife electrotomy technology, which can resolve the stricture without entering the stenotic bile duct, is a safe and effective option. As in the case of patient 12 in this study, guidewire cannot be inserted into strictured bile duct thus failed in balloon expansion and stent placement. Then, PTCD approach was performed as a rescue therapy, but failed again. Cholangiography and ERCP both showed that the stricture was a completely obstructed stricture and its length was about $6 \mathrm{~mm}$. Finally, one-step PTC combined with high-frequency needle-knife electrotomy was conducted to solve this stricture and achieved stricture resolution. After the strictured opening was cut, the balloon dilatation catheter could be inserted under the guidance of guidewire(figure4).

The devices and techniques used to treat the strictures varied among studies with various outcomes. Some systematic reviews reported that patients treated with covered self-expandable metal stent(SEMS)got stricture resolution rates between $80 \%$ and $95 \%$ when the stent was left in place for 3 months or longer[21]. In comparison, patients who received plastic stents treatment were similar with respect to stricture resolution, but SEMS required fewer interventions compared to plastic stents[22-24]. Our outcomes were consistent with those of the above studies.

In the study by Yulong et al, the feasibility and effectiveness of choledochoscopic high-frequency needle-knife electrotomy have been verified in the treatment of intrahepatic biliary stricture[11]. After the initial electrotomy, guidewire and balloon dilatation catheter could get across the strictured bile duct in cases of serious tubular strictures which were often failed in ERC approach. Up till now, there has been no study to use this technique in treating biliary strictures after liver transplantation, thus this is the first report applying choledochoscopic high-frequency needle-knife electrotomy in biliary strictures after liver transplantation.

Unlike traditional PTC which need multiple sessions to establish a fistulous channel in several days, one-step PTC can establish a channel for a rigid cholangioscope in one operation. With the aid of PTOBF, the sinus could be expanded to a suitable size $(16-18 \mathrm{Fr})$

after percutaneous biliary puncture. It can not only provide a working channel of cholangioscopy, but also a channel to insert $12 \mathrm{Fr}$ drainage catheter as stricture supporting.

This supporting catheter is cheap, easy to implement, and can be easily exchanged and removed. Therefore, the combination of one-step PTC and choledochoscopic high-frequency needle-knife electrotomy can provide possibility for treating complicated hepatolithiasis and refractory strictures at the same time.

As for study limitations, this work was limited by the small number of cases, and hence unable to set a control group. Besides, prospective multicenter studies involving a larger population are needed to evaluate its effects.

\section{Conclusions}

In conclusion, the combination of one-step PTC and choledochoscopic high-frequency needle-knife electrotomy can treat complicated hepatolithiasis and refractory strictures at the same time. It appears to be useful for treating biliary strictures after liver transplantation.

\section{Declarations}

Corresponding author: Ping Wang, MD, Department of Hepatobiliary Surgery, The First Affiliated Hospital of Guangzhou Medical University, Guangdong Province, China 510120. Email: wangping_dr@126.com.

Funding sources: the Guangdong Science and Technology Program (grant no. 2017ZC0222); and the Guangzhou Minsheng Science and Technology Research Program (grant no. 201803010065) ; the Guangzhou Science and technology plan project \grant no.201702040215区

Disclosure: Drs. Tao, Wang, Sun, Zhou and Xie have no conflicts of interest or financial ties to disclose.

\section{Author contributions}

Study conception and design: Haisu Tao

Acquisition of data: Haisu Tao, Ping Wang, Beiwang Sun, Xinghua Zhou

Analysis and interpretation of data: Haisu Tao, Ping Wang, Jiafen Xie 
Drafting of manuscript: Haisu Tao, Ping Wang,

\section{References}

1. Larghi A, Tringali A, Rimbaş M, et al. Endoscopic Management of Benign Biliary Strictures After Liver Transplantation. Liver Transplantation 2019; 25(2):323-335.

2. Halliday N, Westbrook RH. Liver transplantation: need, indications,patient selection and pre-transplant care. Br J Hosp Med(Lond) 2017;78:252-259.

3. Shah SA, Grant DR, McGilvray ID, et al. Biliary strictures in 130 consecutive right lobe living donor liver transplant recipients:results of a Western center. Am J Transplant 2007; 7: 161-167.

4. Hwang S, Lee SG, Sung KB, et al. Long-term incidence, risk factors, and management of biliary complications after adult living donor liver transplantation.Liver Transpl 2006; 12: 831-838.

5. Chang JH, Lee I, Choi MG, Han SW. Current diagnosis and treatment of benign biliary strictures after living donor liver transplantation. World J Gastroenterol 2016; 22: 1593-1606.

6. Rao HB, Prakash A, Sudhindran S, Venu RP. Biliary strictures complicating living donor liver transplantation: Problems, novel insights and solutions. World Journal of Gastroenterology 2018; 24(19):2061-2072.

7. Hsieh TH, Mekeel KL, Crowell MD, et al. Endoscopic treatment of anastomotic biliary strictures after living donor liver transplantation: outcomes after maximal stent therapy. Gastrointest Endosc 2013; 77: 47-54

8. Rao HB, Ahamed H, Panicker S, et al.Endoscopic therapy for biliary strictures complicating living donor liver transplantation: Factors predicting better outcome. World J Gastrointest Pathophysiol 2017; 8: 77-86

9. Trikudanathan G. Endoscopic management of difficult commonbile duct stones. World J Gastroenterol 2013;19:165.

10. Lamanna A, Maingard J, Tai J, et al. Percutaneous transhepatic Laser lithotripsy for intrahepatic cholelithiasis. Diagn Interv Imaging 2019; 100(12):793-800.

11. Yang YL, Zhang C, Zhao G, et al. Choledochoscopic high-frequency needle-knife electrotomy as an effective treatment for intrahepatic biliary strictures. J Gastroenterol Hepatol 2015; 30(9):1438-43.

12. Tao H, Wang P, Sun B, et al. One-Step Multichannel Percutaneous Transhepatic Cholangioscopic Lithotripsy Applied in Bilateral Hepatolithiasis. World J Surg 2020; 30(9):1438-43.

13. Wang P, Sun B, Huang B, et al. Comparison between percutaneous transhepatic rigid cholangioscopic lithotripsy and conventional percutaneous transhepatic cholangioscopic surgery for hepatolithiasis treatment. Surg Laparosc Endosc Percutaneous Tech 26(1):54-59.

14. Tarantino I, Amata $\mathrm{M}$, Cicchese $\mathrm{N}$, et al. Sequential multistenting protocol in biliary stenosis after liver transplantation: a prospective analysis. Endoscopy 2019; 51(12):1130-1135.

15. Cantù $P$, Tarantino I, Baldan A, et al. Endo-therapies for biliary duct-to-duct anastomotic stricture after liver transplantation: Outcomes of a nationwide survey. Liver International 2019; 39(7):1355-1362.

16. Kim ES, Lee BJ, Won JY, et al. Percutaneous transhepatic biliary drainage may serve as a successful rescue procedure in failed cases of endoscopic therapy for a post-living donor liver transplantation biliary stricture. Gastrointestinal Endoscopy 2009; 69(1):38-46.

17. Li Y, Sun H, Yan X, et al. Magnetic compression anastomosis for the treatment of benign biliary strictures: a clinical study from China. Surgical Endoscopy 2019.

18. Cheung MT, Wai SH, Kwok PC, et al. Percutaneous transhepatic choledochoscopic removal of intrahepatic stones. Br J Surg 90(11):1409-1415.

19. Huang $\mathrm{MH}$, Chen $\mathrm{CH}$, Yang JC, et al. Long-term outcome of percutaneous transhepatic cholangioscopic lithotomy for hepatolithiasis.Am J Gastroenterol 98:2655-2662.

20. Chen $\mathrm{CH}$, Huang MH, Yang JC, et al. Reappraisal of percutaneous transhepatic cholangioscopic lithotomy for primary hepatolithiasis. Surg Endosc 19(4):505-509.

21. Kao D, Zepeda-Gomez S, Tandon P, Bain VG. Managing the post-liver transplantation anastomotic biliary stricture: multiple plastic versus metal stents: a systematic review. Gastrointest Endosc 2013;77:679-691.

22. Martins FP, De Paulo GA, Contini MLC, Ferrari AP. Metal versus plastic stents for anastomotic biliary strictures after liver transplantation: a randomized controlled trial. Gastrointest Endosc 2018; 87: 131.e1-131.e13. 
23. Landi F, de'Angelis N, Sepulveda A, et al. Endoscopic treatment of anastomotic biliary stricture after adult deceased donor liver transplantation with multiple plastic stents versus self-expandable metal stents: a systematic review and meta-analysis. Transpl Int 2018; 31:131-151.

24. Tal AO, Finkelmeier F, Filmann N, et al. Multiple plastic stents versus covered metal stent for treatment of anastomotic biliary strictures after liver transplantation: a prospective, randomized, multicenter trial. Gastrointest Endosc 2017; 86: 1038-1045.

\section{Figures}
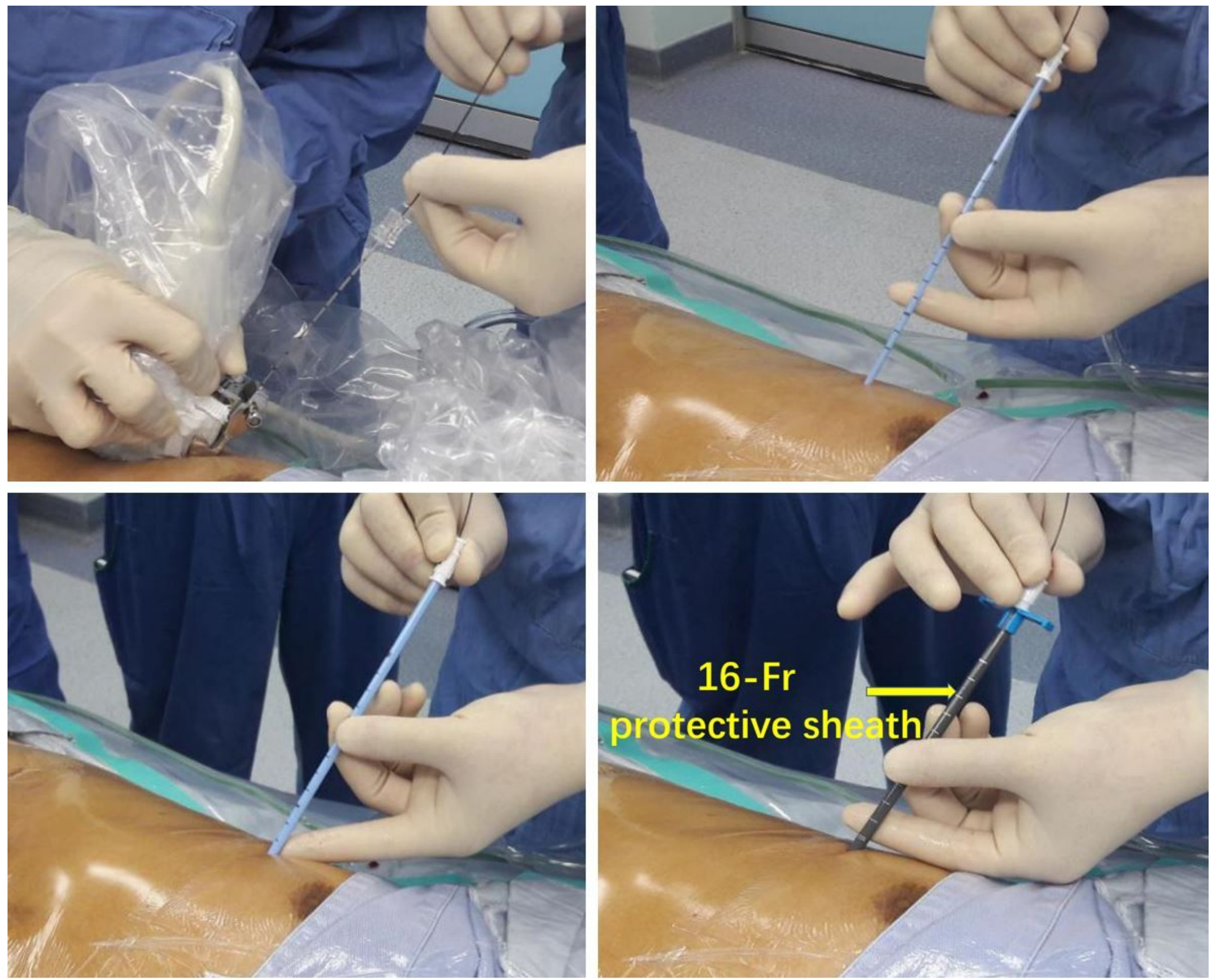

\section{Figure 1}

PTOBF and establishing channel for the rigid choledochoscope 

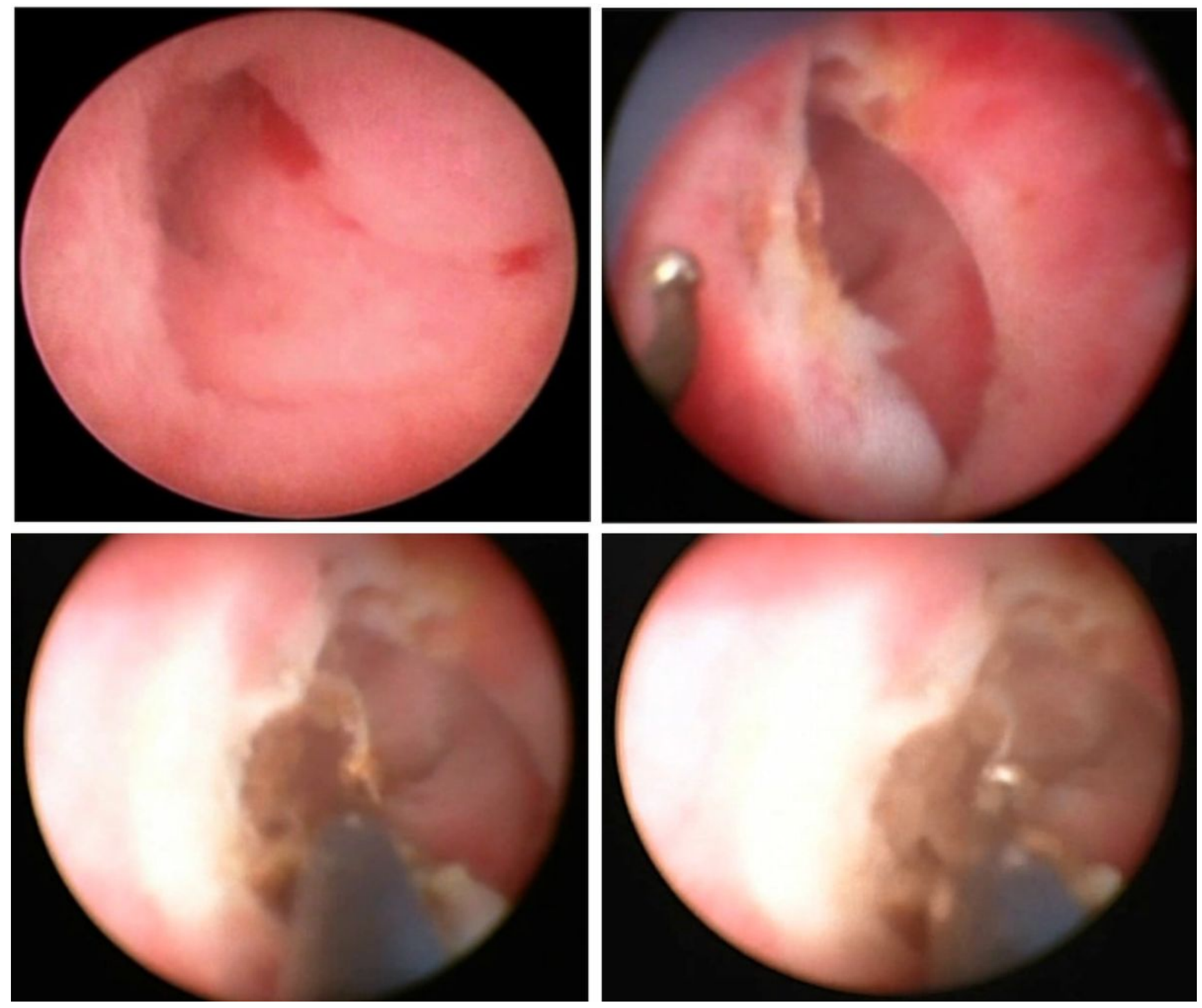

Figure 2

Choledochoscopic needle-knife electrotomy for biliary stricture 

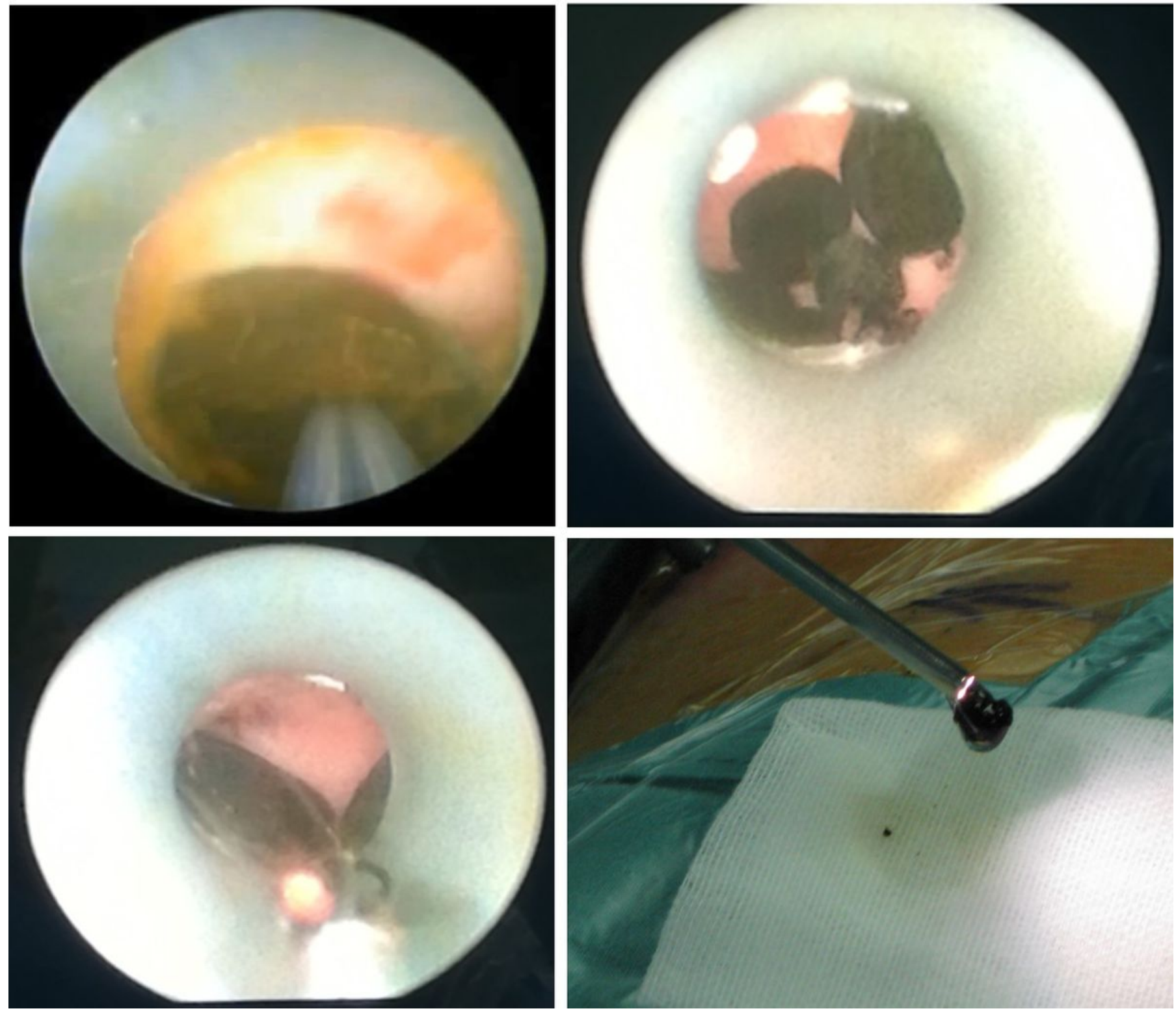

Figure 3

Choledochoscopic lithotripsy and stone removal 

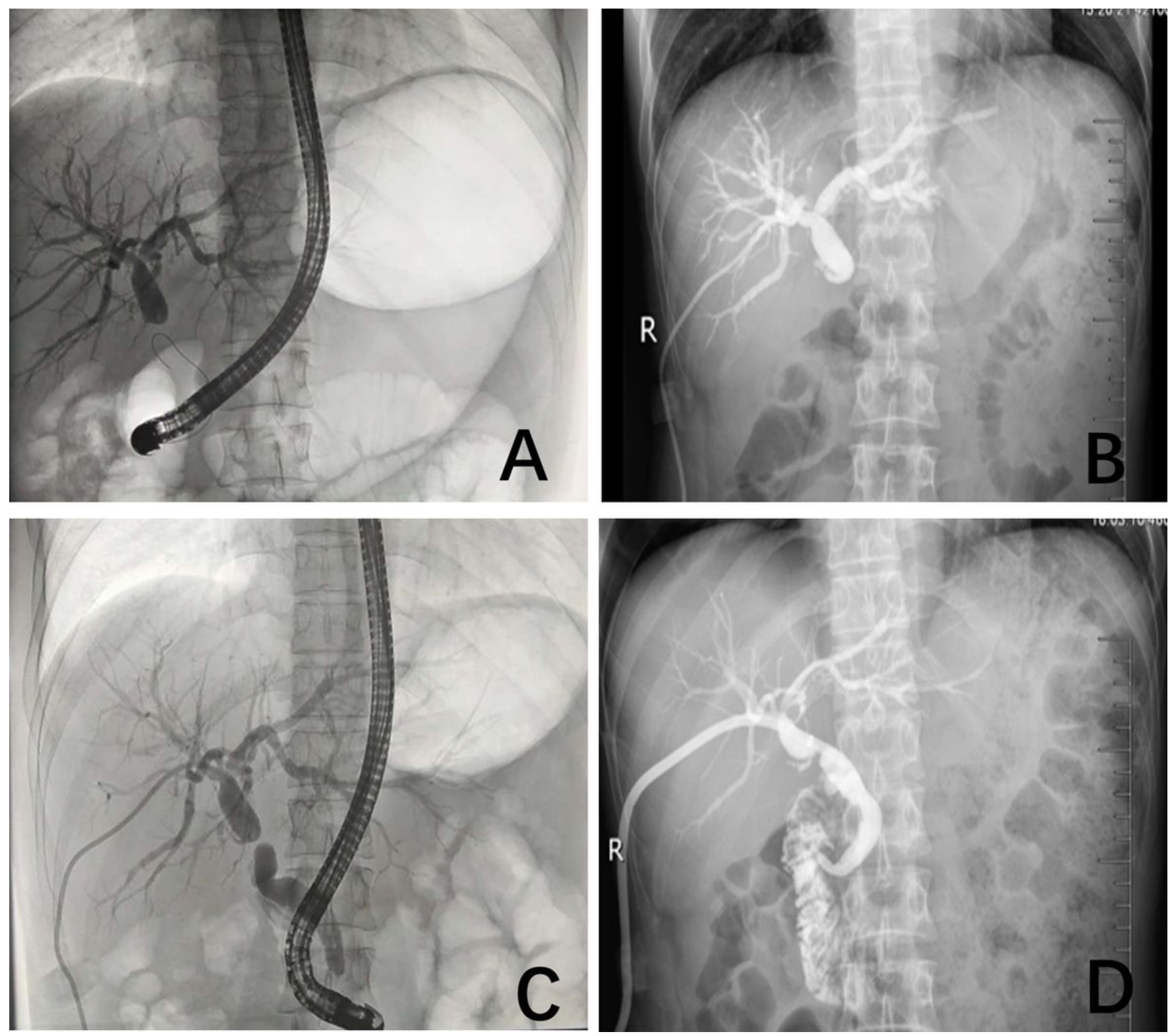

\section{Figure 4}

A. Guidewire cannot be inserted into strictured and PTCD approach was performed as a rescue therapy B. PTCD approach failed again C. Cholangiography and ERCP both showed that the stricture was a completely obstructed stricture and its length was about $6 \mathrm{~mm}$. D. After the strictured choledochoscopic needle-knife electrotomy and balloon dilatation, 12-Fr supporting catheter was placed across the stricture. 